\title{
Carotid and Vertebral Rete Mirabile in Man
}

\author{
-Case Report-
}

\author{
Youichi ITOYAMA, Ikuo KITANO* and Yukitaka USHIO \\ Department of Neurosurgery, Kumamoto University Medical School, Kumamoto; \\ *Division of Neurosurgery, Minamata City Medical Center, Minamata, Kumamoto
}

\begin{abstract}
Rete mirabile is a normal vascular network in the carotid artery distribution of some vertebrates, but is an abnormal and extremely rare finding in humans. We describe a 40 -year-old male with a carotid and vertebral rete mirabile manifesting as cerebrovascular disorder. This was the second case of carotid and vertebral rete mirabile in man.
\end{abstract}

Key words: rete mirabile, carotid artery, vertebral artery

\section{Introduction}

Carotid rete mirabile is a normal vascular structure in some vertebrates including cats, sheep, goats, cows, and pigs, and consists of a network of vessels between the external carotid artery and the extradural portion of the internal carotid artery, usually located near the cavernous sinus, and is a major feeder of the circle of Willis. ${ }^{3)}$ Carotid rete mirabile is ordinarily associated with hypoplasia or aplasia of the internal carotid artery, ${ }^{3)}$ and primitive carotid rete mirabile occurs in dogs whose internal carotid arteries are relatively well developed. ${ }^{9)}$

In humans, carotid rete mirabile is an abnormality, with only seven reported cases mostly located in the carotid cavernous portion. Only one case had both carotid and vertebral rete mirabile. Here, we report the second case of carotid and vertebral rete mirabile and discuss the diagnosis and pathogenesis.

\section{Case Report}

A 40-year-old male experienced right hemiparesis and seizure at 4 years of age, and had since received anticonvulsant agents. Neurological examination at our institution disclosed only right hemiparesis. Physical examination showed no abnormalities.

Skull roentgenograms showed enlargement of the

Received September 7, 1992; Accepted December 2, 1992

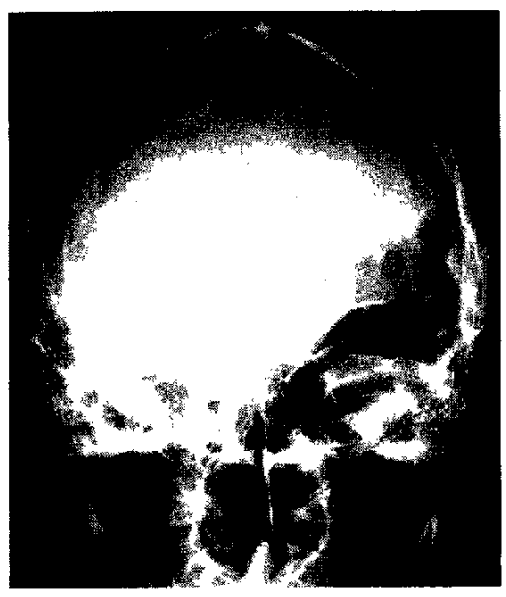

Fig. 1 Skull roentgenogram, anteroposterior view, showing enlargement of the left frontal sinus and superior orbital fissure.

left frontal sinus and the superior orbital fissure (Fig. 1). Computed tomographic (CT) scans showed multiple cerebral infarctions mainly in the left cerebral hemisphere and enlargement of the left frontal sinus (Fig. 2). The bone window CT scan of the skull base showed persistence of the internal carotid canal.

Under the diagnosis of cerebral vascular disorder, a four-vessel study using Seldinger's method (intraarterial digital subtraction angiography: IA-DSA) was performed. The right carotid angiogram showed obstruction of the internal carotid artery before the 


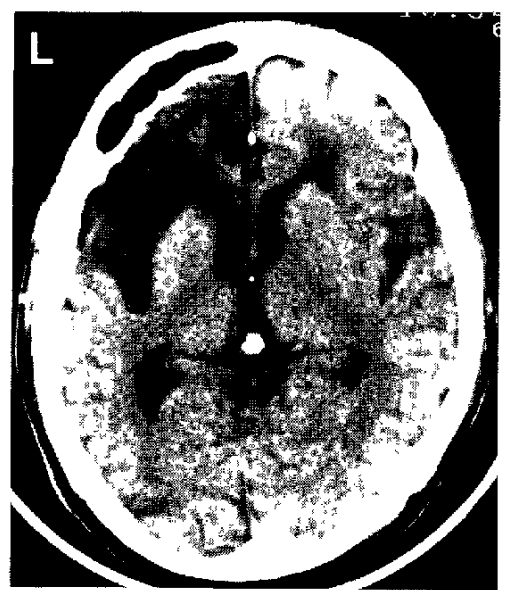

Fig. 2 CT scan, showing multiple cerebral infarctions mainly in the left hemisphere.

cavernous portion and a network formation (rete mirabile) in the cavernous sinus. This network was supplied by the internal carotid and internal max- illary arteries, and drained by the supraclinoid portion of the internal carotid artery. The middle cerebral and the anterior cerebral arteries were faintly visualized. Transdural anastomoses from the middle meningeal, superficial temporal, and occipital arteries were noted (Fig. 3). No abnormality was seen in the venous phase. The left carotid angiogram showed carotid rete mirabile in the cavernous portion similar to the right side, a transdural anastomosis from the posterior auricular artery, and an anastomosis between the carotid and vertebral arteries with muscular branches (Fig. 4). The left vertebral angiogram showed a network formation (rete mirabile) at the occipito-atlantal junction. The supratentorial vascular structures were well supplied from the vertebrobasilar system via well-developed posterior communicating arteries (Fig. 5). The right vertebral angiogram showed vertebral rete similar to the left side and transdural anastomosis via the muscular branches (Fig. 6).

He is now followed up at the outpatient department of our institute uneventfully under the ad-

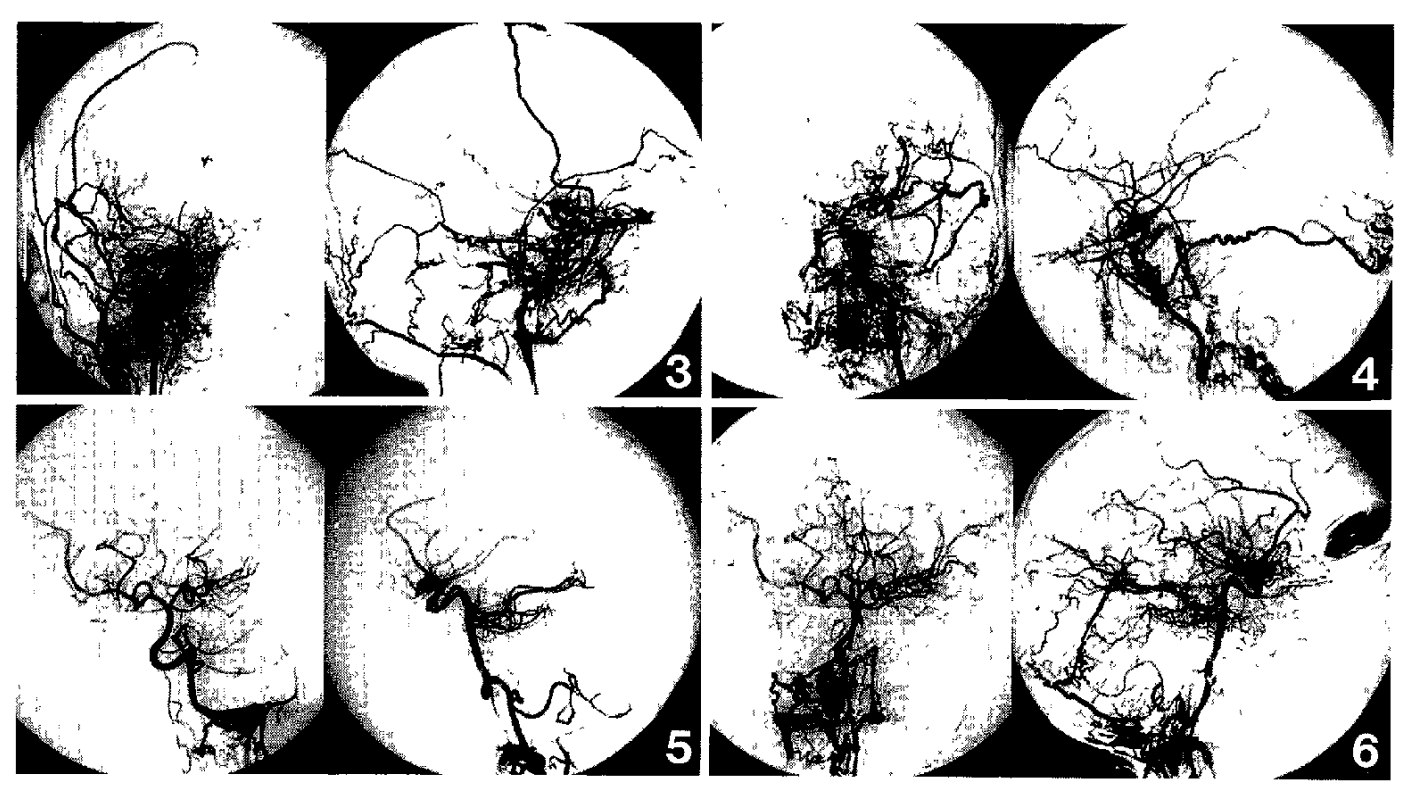

Figs. 3-6 Four-vessel study by IA-DSA.

Fig. 3 Right carotid angiograms, showing carotid rete mirabile in the cavernous portion and transdural anastomosis from the external carotid arteries. left: anteroposterior view, right: lateral view.

Fig. 4 Left carotid angiograms, showing carotid rete mirabile, transdural anastomosis from the external carotid arteries, and anastomosis between the carotid and vertebral arteries with muscular branches. left: anteroposterior view, right: lateral view.

Fig. 5 Left vertebral angiograms, showing vertebral rete mirabile and a good blood supply to the supratentorial arterial systems via well-developed posterior communicating arteries. left: anteroposterior view, right: lateral view.

Fig. 6 Right vertebral angiograms, showing vertebral rete mirabile and transdural anastomosis via muscular branches. left: anteroposterior view, right: lateral view. 
Table 1 Rete mirabile in man

\begin{tabular}{|c|c|c|c|c|}
\hline Case No. & Author (Year) & Age/Sex & Site & Onset \\
\hline 1 & Minagi and Newton $(1966)^{9)}$ & $43 / \mathrm{M}$ & $\mathrm{CA}$ & loss of balance \\
\hline 2 & Hawkins and Scott $(1967)^{6\}}$ & $37 / \mathbf{M}$ & $\mathrm{CA}$ & SAH with aneurysm \\
\hline 3 & Rockett and Johnson $(1968)^{14)}$ & $40 / \mathrm{M}$ & $\mathrm{CA}$ & $\mathrm{SAH}$ \\
\hline 4 & $\begin{array}{l}\text { Rios-Montenegro et al. }(1972)^{131} \text {, } \\
\text { Koo and Newton }(1972)^{83}\end{array}$ & $20 / \mathrm{M}$ & $\mathrm{CA}, \mathrm{VA}$ & $\mathrm{CCF}$ \\
\hline 5 & Danzinger et al. $(1972)^{4)}$ & $39 / \mathrm{F}$ & CA & fainting, dizziness \\
\hline 6 & Araki et al. $(1986)^{1)}$ & $55 / \mathrm{F}$ & $\mathrm{CA}$ & SAH, RIND \\
\hline 7 & Morimoto et al. $(1987)^{10)}$ & $36 / F$ & $\mathrm{CA}$ & SAH with aneurysm \\
\hline 8 & Present case & $40 / \mathrm{M}$ & $\mathrm{CA}, \mathrm{VA}$ & hemiparesis \\
\hline
\end{tabular}

CA: carotid artery CCF: carotid-cavernous fistula, RIND: reversible ischemic neurological disorder, VA: vertebral artery.

ministration of anticonvulsant and antiplatelet agent.

\section{Discussion}

Table 1 lists the reported and present cases of carotid rete mirabile. ${ }^{1,4,6,8-10,13,14)}$ There were five males and three females, with ages ranging from 20 to 55 years (mean, 38.8 yrs). Three patients presented with cerebral ischemia, one a carotid-cavernous fistula, and four subarachnoid hemorrhage (SAH). Hemodynamic stress was thought to cause the aneurysm formation, because two of four patients with SAH had basilar tip aneurysms. ${ }^{6,10)}$ Two patients had pseudoxanthoma elasticum. ${ }^{1,13)}$ Only one previous and our case had carotid and vertebral rete mirabile. ${ }^{8,13)}$

Moyamoya disease is the most important differential diagnosis. Carotid rete mirabile demonstrates good preservation of the supraclinoid portion of the internal carotid artery and circle of Willis, while occlusion of the internal carotid artery usually occurs at the supraclinoid portion of the internal carotid artery in moyamoya disease.

In mammals, carotid rete mirabile is thought to provide 1) a heat exchanger to prevent overheating of the brain, ${ }^{2,7)}$ and 2) protection of the brain by regulating the pressure and flow of the cerebral blood circulation. ${ }^{5,11)}$ In man, anomalous atavistic development is probably the cause of carotid rete mirabile." Rete mirabile is not seen in any developmental stage of humans, ${ }^{6,12)}$ but some primitive anastomotic channels in the human embryo may reappear in adult life as collateral vessels circumventing an occluded carotid artery. ${ }^{13,14)}$ The exact pathogenesis and clinical significance of rete mirabile in man remain unknown.

\section{References}

1) Araki $Y$, Imai $S$, Saitoh $A$, Ito $T$, Shimizu $K$, Yamada $\mathrm{H}$ : A case of carotid rete mirabile associated with pseudoxanthoma elasticum: A case report. No To Shinkei 38: 495-500, 1986 (in Japanese)

2) Baker MA, Hayward JN: The influence of the nasal mucosa and the carotid rete upon hypothalamic temperature in sheep. $J$ Physiol (London) 198: 561-579, 1968

3) Daniel PM, Dawes JDK, Prichard MML: Studies of the carotid rete and its associated arteries. Philos Trans $R$ Soc Lond [Biol] 237: 173-208, 1953

4) Danzinger $J$, Bloch S, Hefer AG: Bilateral rete carotids in man. A case report. S Afr Med J 46: 14871488,1972

5) Edelman NH, Epstein P, Cherniack NS, Fishman AP: Control of cerebral blood flow in the goat: Role of the carotid rete. Am J Physiol 223: 615-619, 1972

6) Hawkins TD, Scott WC: Bilateral rete carotid in man. Clin Radiol 18: 163-165, 1967

7) Jessen $\mathrm{C}$, Pongratz $\mathrm{H}$ : Air humidity and carotid rete function in thermoregulation of the goat. $J$ Physiol (Lond) 292: 469-470, 1979

8) Koo AH, Newton TH: Pseudoxanthoma elasticum associated with carotid rete mirabile. Case report. $A J R$ 116: 16-22, 1972

9) Minagi $\mathrm{H}$, Newton TH: Carotid rete mirabile in man. A case report. Radiology 86: 100-102, 1966

10) Morimoto A, Hashi $K$, Tanabe $S$, Ando $S$, Imaizumi $\mathrm{T}$, Oota $\mathrm{K}$, Takigami M: Bilateral hypoplasia of the internal carotid artery associated with carotid rete mirabile. Rinsho Hoshasen 32: 178-179, 1987 (in Japanese)

11) Nagel EL, Morgane PJ: Rete mirabile of dolphin: Its pressure-damping effect on cerebral circulation. Science 161: 898-899, 1968

12) Padget DH: The development of the cranial arteries in the human embryo. Contrib Embryol Carneg Instn 212: 207-261, 1948

13) Rios-Montenegro EN, Behrens MM, Hoyt WF: 
Pseudoxanthoma elasticum. Association with bilateral carotid rete mirabile and unilateral carotidcavernous sinus fistula. Arch Neurol 26: 151-155, 1972

14) Rockett JF, Johnson TH Jr: Bilateral rete mirabile intracranial (vascular) anastomosis in man. A case report. Radiology 90: 46-48, 1968
Address reprint requests to: Y. Itoyama, M.D., Department of Neurosurgery, Kumamoto University Medical School, 1-1-1 Honjo, Kumamoto 860, Japan. 